\title{
Grid Interface Challenges and Candidate Solutions for the Compact Linear Collider's (CLIC) Klystron Modulators
}

\author{
D. Aguglia \\ CERN, Geneva, Switzerland \\ M. Jankovic, A. Watson, J. Clare, P. Wheeler \\ University of Nottingham, UK
}

Keywords: CLIC

\begin{abstract}
The Compact Linear Collider (CLIC) is a linear electron-positron accelerator under study at CERN, in view of exploring a new leptons collision energy region $(0.5 \mathrm{TeV}$ to $5 \mathrm{TeV})$. This complex requires $\sim 1600$ klystrons fed by highly efficient and controllable power electronics for a convenient power connection to the utility grid. This paper presents the challenges and evaluates several possible structures for the power system. Discussion are provided regarding the candidate topologies according to the converters' ratings / number and considering reliability, modularity, and redundancy.
\end{abstract}

Presented at: IEEE pulsed power and plasma science conference (PPPS),

San Francisco, USA, June 2013

Geneva, Switzerland

November, 2014 


\title{
GRID INTERFACE CHALLENGES AND CANDIDATE SOLUTIONS FOR THE COMPACT LINEAR COLLIDER'S (CLIC) KLYSTRON MODULATORS
}

\author{
M. Jankovic ${ }^{1}$, A. Watson ${ }^{1}$, J. Clare ${ }^{1}$, P. Wheeler ${ }^{1}$, D. Aguglia ${ }^{2}$ \\ ${ }^{1}$ University of Nottingham, University Park, Nottingham, UK, NG7 2RD, Email: eexmj8@nottingham.ac.uk \\ ${ }^{2} \mathrm{CERN}$ - European Organization for Nuclear Research, CH-1211 Geneva 23, Switzerland
}

\begin{abstract}
The Compact Linear Collider (CLIC) is a linear electron-positron accelerator under study at CERN, in view of exploring a new leptons collision energy region $(0.5 \mathrm{TeV}$ to $5 \mathrm{TeV})$. This complex requires $\sim 1600$ klystrons fed by highly efficient and controllable power electronics for a convenient power connection to the utility grid. This paper presents the challenges and evaluates several possible structures for the power system. Discussion are provided regarding the candidate topologies according to the converters' ratings / number and considering reliability, modularity, and redundancy.
\end{abstract}

\section{I.INTRODUCTION}

The CLIC is the highest energy electron-positron linear collider under feasibility study at CERN. The aim of CLIC is to explore the next generation of high precision / high energy particles physics after the Large Hadron Collider (LHC) era [1]. It is based on a two-beams acceleration principle [2]: electron and positron main linacs with high accelerating gradient of $100 \mathrm{MV} / \mathrm{m}$; and two drive beams that produce short high power RF pulses supplying the accelerating structures of the main linacs [3]. The two drive beams require approximately 1600 high power Klystrons and associated modulators. All klystron modulators are operated synchronously and should provide pulsed voltages at $150 \mathrm{kV}, 24 \mathrm{MW}$, with usable flat-top duration of $140 \mu$ s and a pulse repetition rate of $50 \mathrm{~Hz}$. The global pulsed peak power is $39 \mathrm{GW}$. To avoid power quality issues (power fluctuation, voltage flicker, etc.) on the AC utility grid, the synchronous pulsed effects of the klystron modulators must be attenuated by the power electronics converters, which should draw only the required constant average power. As presented in [4], classical klystron modulator systems include a pulse forming system and an AC/DC capacitor bank charger as an interface to the grid. The focus of this paper is the evaluation of power system topologies to be used as interface between the pulse forming systems and the AC grid (capacitor banks charger system and local grid layout). Further information about the modulator system can be found in $[1,4]$.To guarantee very high accelerator availability, high reliability, redundancy and efficiency of the power converters interface are required. The relevant specifications for the power system used as a grid interface are presented in Table 1. Klystron modulators pulse-to-pulse repeatability requirements are very tight, and this specification is directly linked to the repeatability of the DC charging voltage provided by the grid interface system (charger). This is achieved with sophisticated control algorithms of the pulse forming system as well as the charging units.

Table 1. Charger specifications.

\begin{tabular}{|l|c|c|}
\hline \multicolumn{1}{|c|}{ Description } & Label & Specification \\
\hline Charger total power & $P_{c h}$ & $300 \mathrm{MW}$ \\
\hline Modulator's peak power & $P_{\text {peak mod }}$ & $24 \mathrm{MW}$ \\
\hline $\begin{array}{l}\text { Modulator's average } \\
\text { power }\end{array}$ & $P_{\text {mod }}$ & $180 \mathrm{~kW}$ \\
\hline Charger efficiency & $\eta_{c h}$ & $\geq 96 \%$ \\
\hline $\begin{array}{l}\text { Nominal charger DC } \\
\text { voltage }\end{array}$ & $V_{c h}$ & $10 \mathrm{kV}$ \\
\hline Charger DC voltage droop & $\Delta V_{c h}$ & $\leq 2 \mathrm{kV}$ \\
\hline $\begin{array}{l}\text { Pulse-to-pulse } \\
\text { repeatability }\end{array}$ & $\mathrm{PPR}$ & $10 \mathrm{ppm}$ \\
\hline AC power fluctuation & $\delta P_{A C}$ & $\leq 2 \%$ \\
\hline
\end{tabular}

The utility Grid Connection Point (GCP) for the CLIC supplying is a $400 \mathrm{MW}$ nominal power lines at $400 \mathrm{kV}$, provided by Electricité de France (EDF). Existing accelerators at CERN are already supplied from this point via $400 \mathrm{kV} / 18 \mathrm{kV}, \quad 400 \mathrm{kV} / 66 \mathrm{kV}$ and $66 \mathrm{kV} / 18 \mathrm{kV}$ transformers. For standardization and usage of available grid equipment's (e.g. circuit-breakers), the same voltage levels shall be considered for the CLIC. The grid specifications and power connection capabilities versus voltage levels are given in Table 2 .

Table 2. Grid specifications.

\begin{tabular}{|l|c|c|}
\hline \multicolumn{1}{|c|}{ Description } & Label & Specification \\
\hline Voltage at GCP & $V_{\text {grid }}$ & $400 \mathrm{kV}$ \\
\hline Nominal power at GCP & $P_{\text {grid }}$ & $400 \mathrm{MW}$ \\
\hline $18 \mathrm{kV}$ bus-bar max. power & $P_{18 \mathrm{kV}}$ & $90 \mathrm{MVA}$ \\
\hline 66kV bus-bar max. power & $P_{66 \mathrm{kV}}$ & $340 \mathrm{MVA}$ \\
\hline
\end{tabular}


The maximal apparent powers versus voltage levels of Table II derive from the maximal ratings of standard circuit-breakers. Since the average power of the system is rated at around $300 \mathrm{MW}$, a single $400 \mathrm{kV} / 66 \mathrm{kV}$ transformer and single $66 \mathrm{kV}$ bus-bar can be considered for supplying the capacitor charger system. Alternatively, four $400 \mathrm{kV} / 18 \mathrm{kV}$ transformers and four $18 \mathrm{kV}$ bus-bars can be foreseen.

The tight specifications in terms of efficiency, repeatability and maximum $\mathrm{AC}$ power fluctuation, open a wide variety of possibilities for the power system design and topology selection.

All power system structures for the CLIC charging system can be divided into:

1. Single stage conversion structures - considering a direct $\mathrm{AC} / \mathrm{DC}$ conversion.

2. Double-stage conversion structures - considering $\mathrm{AC} / \mathrm{DC}$ and $\mathrm{DC} / \mathrm{DC}$ conversion.

Section II presents all possible structures for the power system. Cable type and length are greatly influencing the DC power quality and efficiency, driving the selection of the global power system solution. All 1600 Klystron modulators are distributed along a $2.5 \mathrm{~km}$ long building [3]. Two adjacent klystrons supply different drive beams, as shown in Fig. 1. The grid connection point is assumed to be $1 \mathrm{~km}$ far from the drive-beams building.

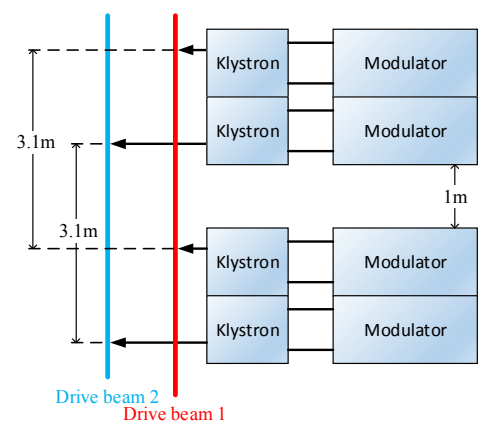

Figure 1. Considered integration of klystron modulators.

Considered possibilities for the charger systems were all solutions between two extreme cases:

1. One charger system per klystron modulator (1600).

2. One centralized charger system for the whole complex.

An overview of solutions within these limits is presented in what follows. Since redundancy and reliability are essential, modular multilevel topologies with the potential for inherent component redundancy are promising candidates.

\section{II.POWER SYSTEM STRUCTURES}

The charger system can be observed as a single voltage source converter (VSC): converting three phase AC voltage to $10 \mathrm{kV}$ DC voltage. The simplified diagram of the grid connected voltage source converter is presented in Fig. 2. In order to make system controllable the amplitude of the grid voltages must be lower than the amplitude of the converter DC voltage. Considering this, the maximum RMS line to line AC voltage corresponding to specific DC output voltage is given by Eq. (1), considering a converter which can only utilize half of the DC link voltage (i.e. all phases connected to a common $\mathrm{DC}$ link). For a DC output voltage of $10 \mathrm{kV}$, the $\mathrm{AC}$ voltage should be around $6 \mathrm{kV}$.

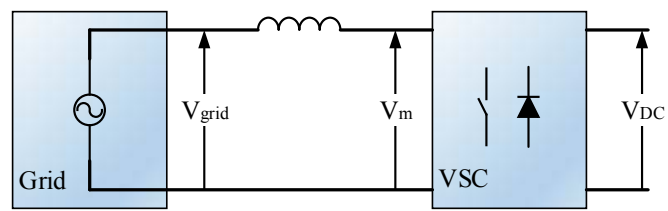

Figure 2. Grid connected voltage source converter.

$$
V_{A C}=\sqrt{3} \cdot \frac{1}{\sqrt{2}} \frac{V_{D C}}{2}
$$

For a charger with a single $\mathrm{AC} / \mathrm{DC}$ converter, converter ratings would be $6 \mathrm{kV}$ and $29 \mathrm{kA}$ on the $\mathrm{AC}$ side, and $10 \mathrm{kV}$ and $30 \mathrm{kA}$ on the DC side. Such a converter configuration is not feasible due to many reasons: semiconductors would need to have enormous current ratings in comparison to voltage ratings; internal storage elements would be rated for high currents; both AC and DC cables have limited current capacity (for underground XLPE aluminum and copper cables this is around 1000A) - many cables would need to be connected in parallel to provide 30kA currents. Although, 300MW AC/DC conversion can be achieved with single converter using high voltage direct current (HVDC) topologies, in this case that is not feasible. The reasonable maximum current ratings for both cables and semiconductors are around $1 \mathrm{kA}$, and this will be crucial for the calculation of the maximum power ratings of a single $\mathrm{AC} / \mathrm{DC}$ converter and the smallest number of converters in the system.

As explained before, in case of single-stage $\mathrm{AC} / \mathrm{DC}$ conversion, voltage on the AC side is about $6 \mathrm{kV}$. Available grid voltages are $18 \mathrm{kV}$ and $66 \mathrm{kV}$, meaning that $18 \mathrm{kV}$ to $6 \mathrm{kV}$ or $66 \mathrm{kV}$ to $6 \mathrm{kV}$ transformers need to be utilized. Alternatively, AC/DC converters can be directly connected to available bus-bars $-18 \mathrm{kV}$ and $66 \mathrm{kV}$, providing DC voltages of $30 \mathrm{kV}$ and $110 \mathrm{kV}$, respectively. In those cases second stage of conversion must be introduced by using voltage step-down DC/DC converters.

Structures with a single-stage and double-stage conversion are presented separately. Minimum and maximum numbers of converters are analyzed in both cases.

\section{A. Single-stage conversion, the smallest number of AC/DC converters}


When single-stage conversion is used, step down transformers provide $6 \mathrm{kV}$ AC voltages at the converters' inputs. The transformers can be connected either to the $18 \mathrm{kV}$ or $66 \mathrm{kV}$ bus-bar. For the lowest number of $\mathrm{AC} / \mathrm{DC}$ converters, the DC current rating is assumed to be approximately $1 \mathrm{kA}$, giving the single converter power of $10 \mathrm{MW}$. The total power system contains about $30 \mathrm{AC} / \mathrm{DC}$ converters where each of them supplies about 55 Klystron modulators. Such a structure, supplied from $18 \mathrm{kV}$ busbars, is presented in Fig. 3. The same number of converters can be supplied from a single $66 \mathrm{kV}$ bus-bar. The selection of $18 \mathrm{kV}$ or $66 \mathrm{kV}$ will be made by comparison of the total impedances seen from the converters side, which includes step-down $6 \mathrm{kV}$ transformer.

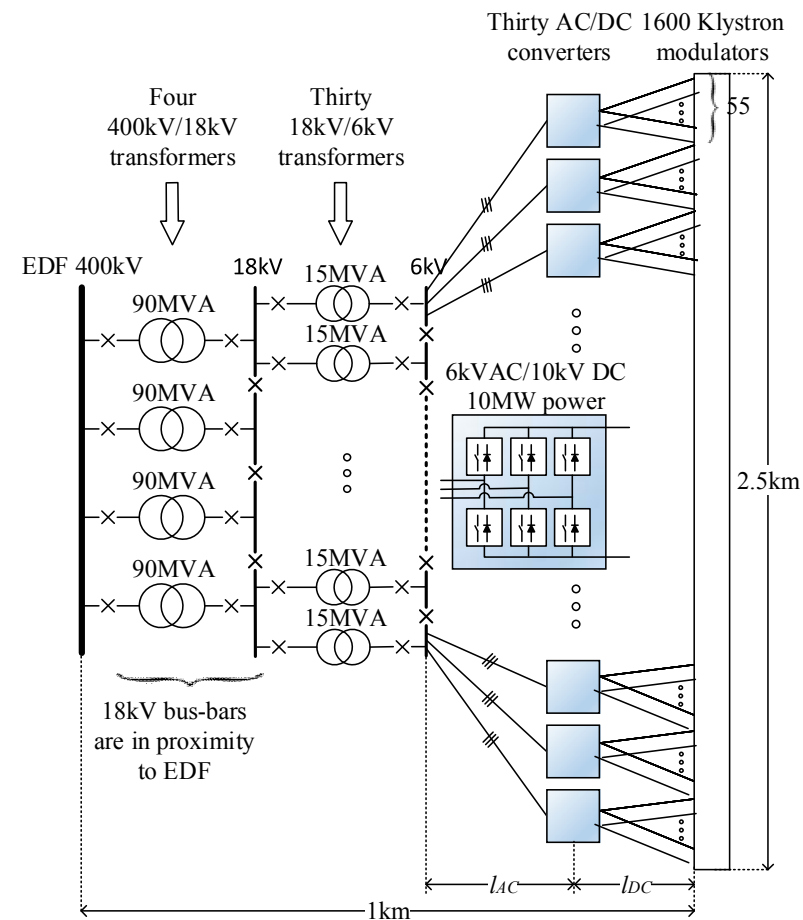

Figure 3. Power system distribution with the smallest number of $\mathrm{AC} / \mathrm{DC}$ converters in case of single-stage conversion and usage of $18 \mathrm{kV}$ bus-bars.

In the presented structure the number of $18 \mathrm{kV} / 6 \mathrm{kV}$ transformers is equal to the number of converters. These transformers and the associated $6 \mathrm{kV}$ bus-bars can be placed anywhere in between the grid and $\mathrm{AC} / \mathrm{DC}$ converters. Without losing any generalization, the number of transformers can be optimized accordingly to the feasible power ratings and impedances of a single transformer. The position of the $6 \mathrm{kV}$ bus-bars and the $\mathrm{AC} / \mathrm{DC}$ converters will unambiguously determine the AC and DC cable lengths. The cable length (and position of bus-bars and converters) should be optimized in correspondence to the total cable length, electrical efficiency of the cables, and influence of cables on signal quality. DC lines are preferably as short as possible, because of their influence on the DC voltage and current that is typically controlled on the converter side. Additionally, long DC lines might cause a need for two capacitor banks: the necessary one on the modulators side, and additional one on the converter side.

In order to provide specified power rating and to fulfill redundancy requirements, modular multilevel HVDC topologies should be used. The most promising topologies are Modular Multilevel Converter (MMC) introduced in [5], and Parallel Hybrid - Modular Multilevel Converter (PH-M2C) introduced in [6]. Additional hybrid HVDC topology being considered is Alternating Arm Multilevel Converter (AAMC) presented in [7].

\section{B. Single-stage conversion, the largest number of AC/DC converters}

The single-stage conversion structure with the largest number of $\mathrm{AC} / \mathrm{DC}$ converters considers that one converter supplies a single modulator, giving the converter rated power of approximately $180 \mathrm{~kW}$ and DC current $18 \mathrm{~A}$. Similarly to the previous case voltage step-down transformers must be used to provide $6 \mathrm{kV}$ AC voltages on converters' inputs. The selection of $66 \mathrm{kV}$ or $18 \mathrm{kV}$ busbars would be carried out according to the total impedances seen from converter. The power system structure in the case of the $18 \mathrm{kV}$ bus-bar connection is shown in Fig. 4.

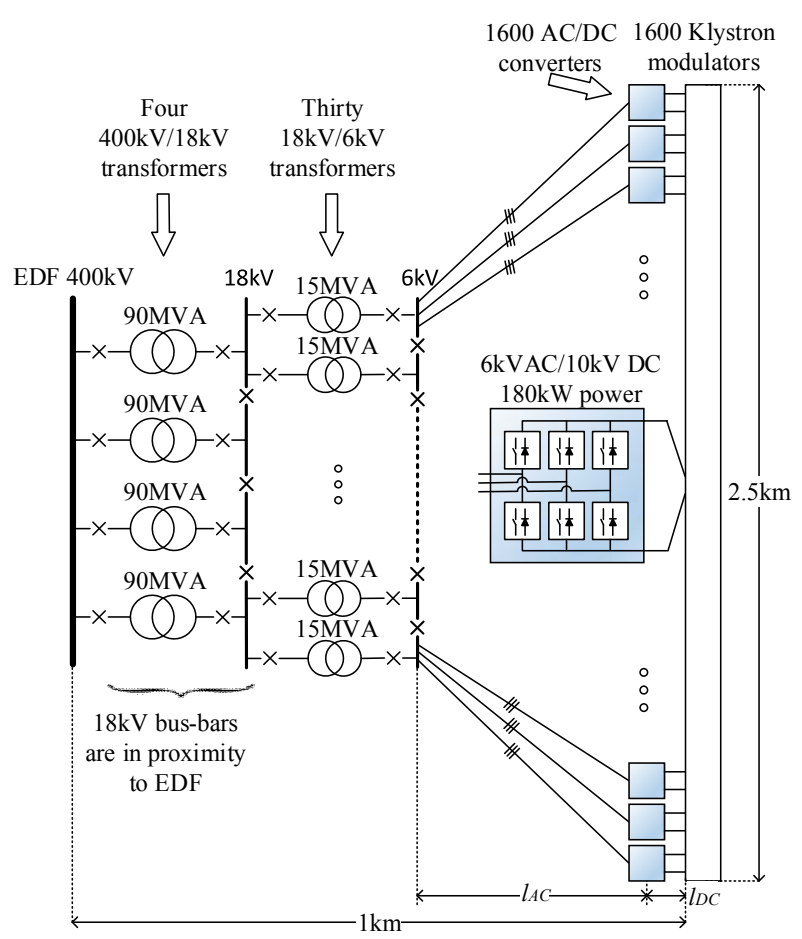

Figure 4. Power system distribution with the largest number of $\mathrm{AC} / \mathrm{DC}$ converters in case of single-stage conversion and usage of $18 \mathrm{kV}$ bus-bars.

The presented structure has thirty $18 \mathrm{kV} / 6 \mathrm{kV}$ transformers, but the number of transformers can be 
higher, up to 1600 . In case that there is single transformer per converter each transformer can be placed in proximity to the corresponding converter. Alternatively, when many converters have common transformers and bus-bars, the position of both transformers and bus-bars will be closer to the grid.

Since there is a single converter per modulator, converters are assumed to be located in close proximity to the corresponding modulators. However, the position of transformers, $6 \mathrm{kV}$ bus-bars and converters can be calculated to optimize electrical efficiency and volume of cables. Due to very high number of converters, the number of cables and connections is very high, and optimization of cable length will be more involved. The long cables are underground (a constraint of the site) and so they must fit to the sizes of a tunnel. Specific cables will not follow the shortest route, but the tunnels that minimize the total length of cables.

For such power and voltage ratings, standard converters can be utilized. Possible topologies are Neutral Point Clamp Converter (NPC), dual NPC converter and Flying Capacitor Converter (FCC). A review of those topologies is presented in [8]. None of these topologies naturally offers redundancy, but they are all very simple "off-theshelf" solutions. However, it is possible to add some modifications to improve redundancy and reliability of the topologies. Also, their evaluation for the charger purposes is important in comparison to HVDC topologies.

\section{Double-stage conversion, the smallest number of AC/DC converters}

When double-stage conversion is used, there are no additional transformers, except those providing $18 \mathrm{kV}$ or $66 \mathrm{kV}$ bus-bars. An $\mathrm{AC} / \mathrm{DC}$ converter attached to the $18 \mathrm{kV}$ bus-bar, will provide about $30 \mathrm{kV}$ DC voltage output which need to be converted to the $10 \mathrm{kV}$ DC voltage suitable for the Klystron modulators. DC/DC converters used for this purpose will need to provide a 3:1 step-down ratio. In the case when the $\mathrm{AC} / \mathrm{DC}$ converter is connected to the $66 \mathrm{kV}$ bus-bar, its DC output will be approximately $110 \mathrm{kV}$, meaning that $\mathrm{DC} / \mathrm{DC}$ converter needs to have a step-down ration of 11:1. These large step-down ratios are not preferable, because circuit components must be rated to much higher levels than those effectively used. Therefore, double-stage conversion will consider the connection with four $18 \mathrm{kV}$ bus-bars.

An AC/DC converter's DC current is again assumed to be around $1 \mathrm{kA}$, giving maximum power ratings of $30 \mathrm{MW}$ per single converter. This implies that the smallest number of converters is around 10 . However the number of DC-DC converters is going to be higher, since those are limited to powers up to couple of MW. The structure with ten AC/DC and $100 \mathrm{DC} / \mathrm{DC}$ converters is shown in Fig. 5.

The position of $\mathrm{AC} / \mathrm{DC}$ converters and $\mathrm{DC} / \mathrm{DC}$ converters should be calculated to optimize the volume of the cables and their efficiency and to minimize their effect on the DC power quality.

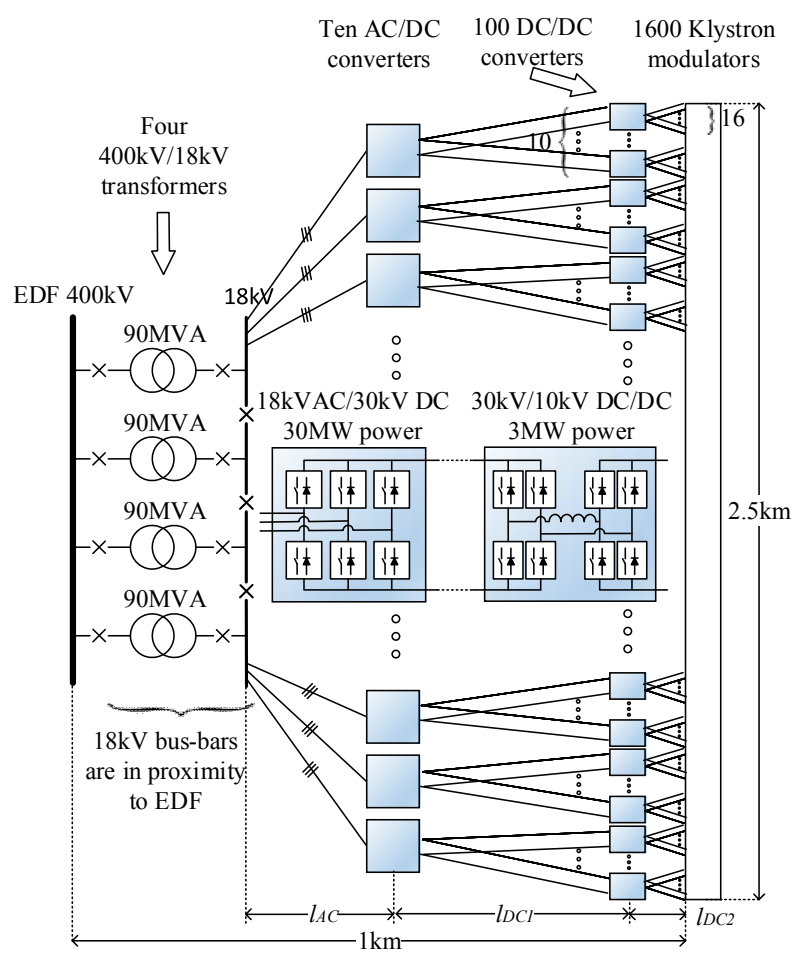

Figure 4. Power system distribution with the smallest number of $\mathrm{AC} / \mathrm{DC}$ converters in case of double-stage conversion and usage of $18 \mathrm{kV}$ bus-bars.

The specified power and voltage rating of $\mathrm{AC} / \mathrm{DC}$ converter corresponds to HVDC topologies, such as $\mathrm{MMC}, \mathrm{PH}-\mathrm{M} 2 \mathrm{C}$ and AAMC. The power rating of $\mathrm{DC} / \mathrm{DC}$ converters is $3 \mathrm{MW}$, corresponding to either an isolated or non-isolated MMC based Dual Active Bridge (DAB) converters. In the case of a higher number of lower power DC/DC converters, standard and resonant DAB converters can be considered. However, voltage levels imply a requirement for multilevel bridges.

\section{Double-stage conversion, the largest number of AC/DC converters}

The largest number of $\mathrm{AC} / \mathrm{DC}$ converters corresponds to the lowest power rating of single converter, which is tightly connected to the topology used. In the case of double-stage conversion, voltage levels are high for standard topologies, so multilevel topologies must be used. Considering a multilevel converter with $30 \mathrm{kV}$ output voltage, a reasonable minimum power rating is about $1 \mathrm{MW}$, i.e. a DC current rating of about $30 \mathrm{~A}$. In this case $300 \mathrm{AC} / \mathrm{DC}$ converters are required, where the number of $\mathrm{DC} / \mathrm{DC}$ converters is the same or higher. The described structure is shown in Fig. 5.

Similarly to the previous case, the length of the AC and DC cables should be optimized. The most promising topologies are MMC and PH-M2C, but another HVDC 
topology is considered, as well. DC/DC converters can either be isolated or non-isolated $\mathrm{DAB}$ or resonant $\mathrm{DAB}$ topologies. The active bridges of the $\mathrm{DAB}$ converters are preferably $\mathrm{MMC}$ based due to voltage and power ratings.

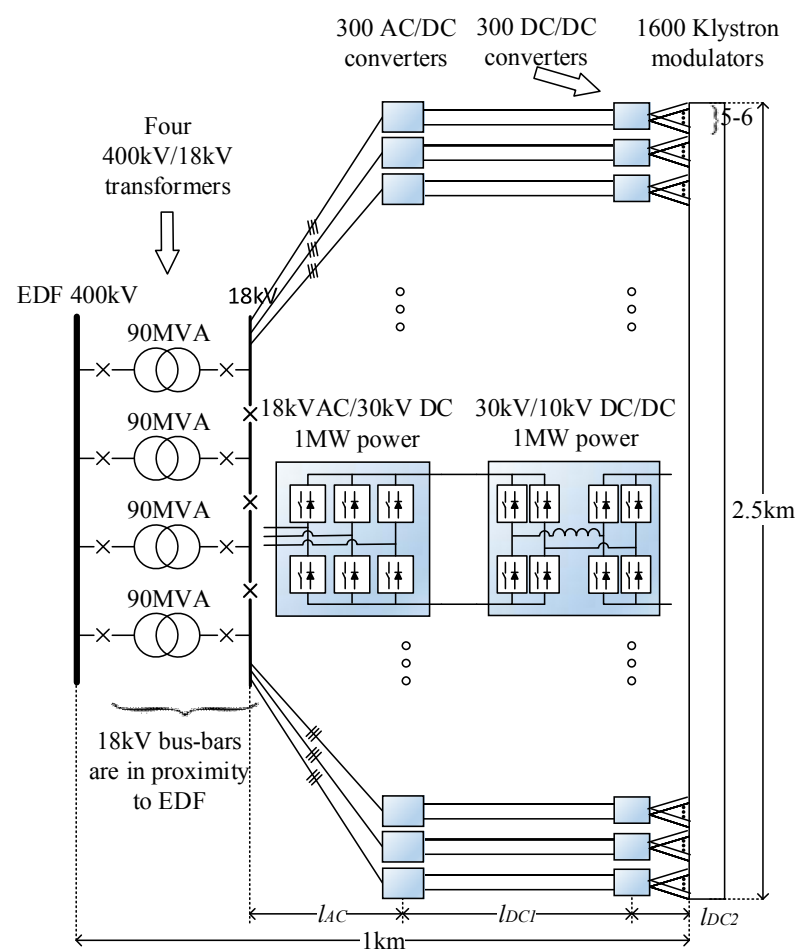

Figure 5. Power system distribution with the largest number of $\mathrm{AC} / \mathrm{DC}$ converters in case of double-stage conversion and usage of $18 \mathrm{kV}$ bus-bars.

\section{CONVERTER TOPOLOGIES}

The topologies used for the charging application, should be highly reliable and (where possible) inherently support redundancy. The power (and voltage) levels considered suit the use of modern multi-level converters. These converters are capable of working on the Medium and High Voltage levels considered for such applications as electrical motor drives, Flexible AC Transmission Systems, and HVDC transmission and are therefore largely mature. Over the last twenty years various topologies, such as the Cascaded H-Bridge and Neutral Point Clamped converters have become industry standard in some of these applications. More recently the Modular Multilevel Converter has gained significant momentum in the HVDC field as a result of its ability to create high quality waveforms on the utility side (requiring minimum filtering) whilst maintaining high efficiency operation.

Various hybrid topologies have recently been published in literature including the Parallel Hybrid Modular Multilevel Converter shown in Fig. 6, and the Alternate Arm Converter - such topologies may increase efficiency over standard MMC converters or offer advantages such as DC side fault ride through (although the latter is not of use in this application). The use of MMC topologies in high power DC/DC converters, as proposed in [9], has also been considered and one particular option, incorporating isolation and the ability to step up/down the voltage is presented in Fig. 7.

The evaluation criteria for these converters are shown in the next section and this is the subject of the continuing work of the project.

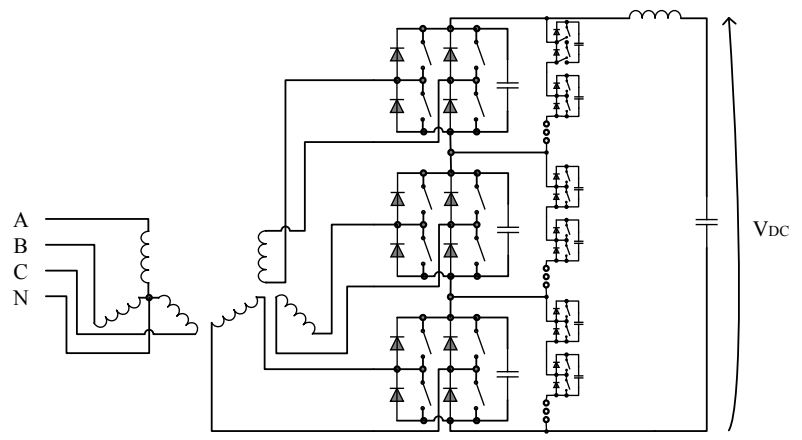

Figure 6. $\mathrm{PH}-\mathrm{M} 2 \mathrm{C}$ Converter.

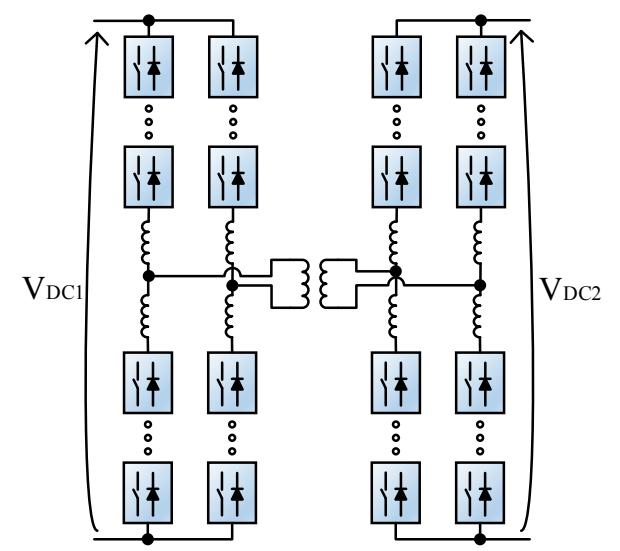

Figure 7. MMC based DC/DC converter.

\section{CRITERIA FOR COMPARISON AND EVALUATION}

Before designing advanced control algorithm to fulfill specifications for AC power fluctuation and DC voltage repeatability, the number of required converters, and topologies should be selected. The section II presented single-stage and double-stage conversion structures, together with maximum and minimum number of converters. An optimal solution can have any number of converters from corresponding range. The optimization process must consider feasible converter ratings. As a result the power system structures and topologies selection must be done simultaneously because properties of one, directly affect properties of other. 
Assuming correct operation of converter, every topology can be evaluated according to its efficiency, redundancy (reliability and influence of additional cells) and volume, as a function of power and voltage rating. Efficiency can be found through the loss calculation. Volume can be approximated by volume of storage elements, e. g. capacitors; and volume of semiconductors. Considering single-stage conversion, depending on number of $\mathrm{AC} / \mathrm{DC}$ converters, the power ratings are uniquely determined, and all topologies fitting to those power ratings can be used. For the chosen number of converters and every possible topology, a corresponding single-stage power system will be evaluated according to cable length, total efficiency (of both cabling and power electronics), volume of semiconductors and storage elements, redundancy, etc. In the case of single-stage conversion there will be a range of converters that correspond to HVDC topologies only, other that correspond to standard topologies only, and a medium range where both multilevel and standard topologies are possible.

Similarly, double-stage structures can be evaluated, through evaluation of relevant properties for specific numbers of $\mathrm{AC} / \mathrm{DC}$ and $\mathrm{DC} / \mathrm{DC}$ converters, and possible topologies. In case of double-stage conversion, only HVDC topologies can be used for the AC/DC conversion stage, whilst for $\mathrm{DC} / \mathrm{DC}$ conversion, due to high voltage and power ratings, only MMC based, non-isolated and isolated DAB topologies are available.

Finally, when all solutions are covered, the most promising structure (number of converters) and topologies would be selected. There are many parameters to be evaluated - total efficiency, redundancy, volume of cables and power electronics - and the most promising solution will most likely be the trade-off of those parameters. The results of the optimization will be the subject of a future paper.

\section{SUMMARY}

This paper presented more technical details about the challenges for the CLIC utility grid connection. Considering the fact that CLIC is based on two-beam acceleration principle, the energy from the grid is primarily used for supplying klystrons and acceleration of the drive beams, that are further used for acceleration of main beams. Design of power system as a grid interface of klystrons was in the focus of this paper.

Two main power system structures were considered: one that include $\mathrm{AC} / \mathrm{DC}$ conversion only and another that include both $\mathrm{AC} / \mathrm{DC}$ and $\mathrm{DC} / \mathrm{DC}$ converters. The scope for number of converters, and their power ratings is presented for both structure types. Various topologies are considered, where the most promising ones are suggested for specific voltage and power ratings. Specifications require high efficiency and reliability, selecting modular multilevel topologies as a natural choice.

However, both topologies and structures should be evaluated and compared to provide selection of the best solution. Advanced control mechanisms of such system should be designed, to meet the requirements, especially those relating to AC power and DC voltage quality. Both power system optimization and control design will be in focus of future research and subject of future papers.

\section{REFERENCES}

[1] D. Aguglia and E. Sklavounou, "Klystron modulators capacitor chargers design compromises for ac power quality increase of the Compact Linear Collider (CLIC)," in Power Electronics, Electrical Drives, Automation and Motion (SPEEDAM), 2012 International Symposium on, 2012, pp. $1535-1541$.

[2] W. Schnell, "A Two-Stage RF Linear Collider Using a Superconducting Drive Linac," in New Techniques for Future Accelerators, 29 ed, 1987, pp. 67-87.

[3] D. Dannheim, P. Lebrun, L. Linssen, D. Schulte, and S. Stapnes. CLIC e+e- Linear Collider Studies - Input to the Snowmass process 2013 [Online].

[4] D. Aguglia, C. A. Martins, M. C. Bastos, D. Nisbet, D. Siemaszko, E. Sklavounou, and P. Viarouge, "Klystron modulator technology challenges for the Compact Linear Collider (CLIC)," in Pulsed Power Conference (PPC), 2011 IEEE, 2011, pp. 1413-1421.

[5] A. Lesnicar and R. Marquardt, "A new modular voltage source inverter topology," presented at the Europian Power Electronics Conference (EPE), Toulouse, France, 2003.

[6] R. Feldman, M. Tomasini, J. C. Clare, P. Wheeler, D. R. Trainer, and R. S. Whitehouse, "A hybrid voltage source converter arrangement for HVDC power transmission and reactive power compensation," in Power Electronics, Machines and Drives (PEMD 2010), 5th IET International Conference on, 2010, pp. 1-6.

[7] M. M. C. Merlin, T. C. Green, P. D. Mitcheson, D. R. Trainer, D. R. Critchley, and R. W. Crookes, "A new hybrid multi-level Voltage-Source Converter with DC fault blocking capability," in $A C$ and $D C$ Power Transmission, 2010. ACDC. 9th IET International Conference on, 2010, pp. 1-5.

[8] J. Rodriguez, L. G. Franquelo, S. Kouro, J. I. Leon, R. C. Portillo, M. A. M. Prats, and M. A. Perez, "Multilevel Converters: An Enabling Technology for High-Power Applications," Proceedings of the IEEE, vol. 97, pp. 1786-1817, 2009.

[9] S. Kenzelmann, A. Rufer, D. Dujic, F. Canales, and Y. R. De Novaes, "A versatile DC/DC converter based on Modular Multilevel Converter for energy collection and distribution," in Renewable Power Generation (RPG 2011), IET Conference on, 2011, pp. 1-6. 